\title{
Associations of frailty and psychosocial factors with autonomy in daily activities: a cross-sectional study in Italian community-dwelling older adults
}

This article was published in the following Dove Press journal:

Clinical Interventions in Aging

II January 2016

Number of times this article has been viewed

\author{
Anna Mulasso' \\ Mattia Roppolo ${ }^{1,2}$ \\ Fabrizia Giannotta ${ }^{3}$ \\ Emanuela Rabaglietti' \\ 'Department of Psychology, University \\ of Torino, Torino, Italy; ${ }^{2}$ Department \\ of Developmental Psychology, \\ Rijksuniversiteit of Groningen, \\ Groningen, the Netherlands; \\ ${ }^{3}$ Department of Psychology, University \\ of Uppsala, Uppsala, Sweden
}

\begin{abstract}
Frailty has been recognized as a risk factor for geriatric adverse events. Little is known of the role of psychosocial factors associated with frailty in explaining negative outcomes of aging. This study was aimed at 1) evaluating the differences in psychosocial factors among robust, prefrail, and frail individuals and 2) investigating whether there was any interaction effect of frailty status with empirically identified clusters of psychosocial factors on autonomy in the activities of daily living (ADLs). Two-hundred and ten older adults (age $73 \pm 6$ years, $66 \%$ women) were involved in this study. Frailty was assessed using an adapted version of the frailty phenotype. The psychosocial factors investigated were depressive symptoms using the 20-item Center for Epidemiologic Studies Depression Scale, social isolation using the Friendship Scale, and loneliness feeling using the eight-item UCLA Loneliness Scale. The autonomy in ADLs was measured with the Groningen Activity Restriction Scale. Thirty-one percent of participants were robust, 55\% prefrail, and 14\% frail. We performed an analysis of covariance which showed differences between robust, prefrail, and frail individuals for all the psychosocial variables: Center for Epidemiologic Studies Depression Scale, $F(2,205)=18.48$, $P<0.001$; Friendship Scale, $F(2,205)=4.59, P=0.011$; UCLA Loneliness Scale, $F(2,205)=5.87$, $P=0.003$, controlling for age and sex. Using the same covariates, the two-way analysis of covariance indicated an interaction effect of frailty with psychosocial factors in determining ADLs, $F(4,199)=3.53, P=0.008$. This study demonstrates the close relationship between frailty and psychosocial factors, suggesting the need to take into account simultaneously physical and psychosocial components of human functioning.
\end{abstract}

Keywords: functional decline, psychological resources, social resources, disability, interaction effect

\section{Introduction}

In Western countries, the percentage of older adults is expected to increase dramatically in the coming decades. According to official projections, ${ }^{1}$ the population aged 65 or older is expected to rise from $17.4 \%$ in 2010 to $29.5 \%$ in 2060 , with a consistent increase of people aged older than 80 (from $4.6 \%$ to $12.0 \%$ in the period between 2010 and 2060). Among the European Union Member States, Italy was one of the "oldest" countries in 2012 , with an aged population of $20.6 \%$. People aged 80 or older were $6.1 \%$ of the total population. ${ }^{2}$ The growing number of older people will probably increase the demands on health care services. Thus, there is the need to intensify knowledge about aging trajectories in order to find the most effective ways to promote health for older adults.

One of the risk factors for and the precursor of adverse geriatric outcomes is frailty. A frail person has a higher risk of loss of autonomy in daily life (ADL), health-related problems, institutionalization, hospitalization, and death, with consequent negative
Correspondence: Mattia Roppolo Department of Psychology, University of Torino, Via Verdi, 10, 10124 Torino, Italy Tel +390 II 6702788

Fax +390116702791

Email mattia.roppolo@unito.it 
influences on the quality of life. ${ }^{3-10}$ In terms of prevalence, about half of older adults have to deal with frailty. In a systematic review, Collard et al reported an average prevalence rate of $10.7 \%$ for frailty and $41.6 \%$ for prefrailty. ${ }^{11}$ However, this data showed enormous variability according to the operational definition adopted. Considering its great impact on people's lives and its high prevalence rate in the aged population, it is worth expanding the concept of frailty.

Frailty has been broadly defined but without achieving consensus. Specifically, two opposing frailty definitions have been developed. The first one considered frailty as a singledimensional construct based on physical functioning and on the biological/physiological state. ${ }^{12-14}$ The main and the best known conceptualization of physical frailty is the one proposed by Fried et al, who defined frailty as a biological syndrome deriving from cumulative declines in different physiological systems and resulting in a loss of reserves and resistance to external stressors. ${ }^{13}$ The operational definition that results is the phenotype of frailty, according to which a frail individual presents three or more of the following five physical components: shrinking, weakness, poor endurance and energy, slowness, and low physical activity level. Physically frail older adults, compared to robust ones, have a poorer quality of life ${ }^{15}$ and a higher risk of disability, health care utilization, hospitalization, admission to nursing home, and mortality., ${ }^{3,16,17}$ Nonetheless, this vision of frailty is limited since it does not include the psychosocial component of human functioning.

Psychological and social features, such as cognitive decline, depression, and low frequency of social contacts, may be related to negative health outcomes. ${ }^{18,19}$ Specifically, the depressive symptomatology and anxiety are associated with greater use of non-mental-health services, onset of disability, and reduced well-being, ${ }^{20,21}$ and isolation, loneliness, and the absence of social support are related to multiple disease outcomes and all-cause mortality. ${ }^{22-24}$ The idea is that not only physical frailty but also a decline in psychological and social functioning can be seen as risk factors for age-related decline. On this basis, the second definition depicted frailty as a multidimensional construct based on physical, psychological, and social components, suggesting that many factors may contribute to frailty in a complex way. ${ }^{25-27}$ In line with the assumptions of the bio-psycho-social model, ${ }^{28,29}$ physical, psychological, and social components of frailty must be seen as integrated concepts that could better explain human functioning. ${ }^{25,30,31}$ Consistent with this vision, Gobbens et al defined frailty as "a dynamic state affecting an individual who experiences losses in one or more domains of human functioning" with, as a consequence, higher risk for adverse outcomes. ${ }^{25}$ Studies in support of this frailty vision are still limited and report controversial findings. For example, Dent and Hoogendijk investigated the impact of psychosocial resources on the relationship between physical frailty, measured with Fried's criteria, and negative outcomes in a sample of patients admitted to hospital. ${ }^{32}$ They showed that frail individuals with low psychosocial factors had an increased likelihood of incurring negative outcomes (mortality, discharge to higher level care, long length of hospital stay, and re-hospitalization) compared to frail people with good psychosocial functioning. Hoogendijk et al conducted similar research on a sample of community-dwelling older adults, but did not find significant interactions between physical frailty and psychosocial resources. ${ }^{33}$ In this case, the outcomes used were functional decline and mortality. Gobbens et al, using the Tilburg Frailty Indicator (TFI), found an effect of physical frailty on disability 1 and 2 years later but not of psychological and social frailty. ${ }^{34}$ However, in another study, they demonstrated that the older adults' quality of life was affected by both the psychological and the social components of the TFI. ${ }^{35}$ Finally, Ament et al did not find any additional effect of psychological and social dimensions of frailty on disability, quality of life, and hospital admission. ${ }^{36}$ However, those authors used a sample of only physically frail individuals. Given the mixed results and methods of assessment, more studies are needed to understand the relationship between physical frailty, psychosocial factors, and negative outcomes in older adults.

In this study, we refer to the multidimensional conceptualization of frailty. However, while this multidimensionality has been theorized, it has not been widely supported by empirical evidence. Our idea is that a multidimensional concept of frailty that takes into account both physical and psychosocial aspects is more useful in understanding the decline in autonomy in older adults. To test this idea, we investigated the contribution of depression, social isolation, and feeling lonely, associated with the frailty phenotype, ${ }^{13}$ in the explanation of ADLs in a sample of Italian communitydwelling older adults. The specific aims were 1) to evaluate differences in psychosocial factors among robust, prefrail, and frail individuals and 2) to investigate the interaction effect of physical frailty status (robust, prefrail, and frail) and empirically identified clusters of psychosocial factors (good, moderate, and low) on the ADLs.

\section{Materials and methods \\ Participants}

The participants of the present study represent a subset of the Italian Regional project "Act on Ageing”, a longitudinal 
3-year study that aimed at analyzing the effects of physical and cognitive interventions on the health of people older than 65 years. Nine hundred individuals were assessed for eligibility, of whom 298 did not meet the inclusion criteria of the research, 232 did not wish to participate, and three were already involved in other studies. A total of 367 older adults participated in the Act on Ageing project. For this paper, data collected at the baseline were used. Excluding missing values from the analysis $(n=157), 210$ participants were considered. The participants' subset $(n=210)$ was not statistically different in terms of demographic characteristics and cognitive, physical, and psychosocial functioning from the whole sample of the Act on Ageing project.

Participants who met the following criteria were included: 1) older than $65 ; 2$ ) able to walk $500 \mathrm{~m}$ without assistance; 3) a Mini-Mental State Examination ${ }^{37}$ (MMSE) score $\geq 25$; 4) a sedentary lifestyle (absence of participation in regular moderate or vigorous physical activity in the previous 5 years); and 5) no severe health problems (eg, uncontrolled hypertension, recent upper or lower extremity fractures, myocardial infarction within the past 1 year). All participants in the study lived in the Piedmont Region and did not need institutional care.

The study was approved by the Ethical Committee of the University of Turin. All participants provided informed consent in accordance with Italian law and the ethical code of the American Psychological Association. ${ }^{38}$ They did not receive any incentives or reward for participating.

In the baseline evaluation, a large amount of data was collected. First, the participants completed a battery of self-reported questionnaires concerning the demographic characteristics, psychosocial adjustment, quality of life, and health condition, in the presence of a trained psychologist in order to clarify any doubts. Second, an expert in physical education and adapted physical activity for older adults administered physical tests. Finally, people with expertise in the field of ergonomics took anthropometric measurements. Data collection was always carried out in the same order and individually for each participant.

\section{Physical frailty measure}

To identify physically frail older adults, an adapted version of the frailty phenotype of Fried et al was used. ${ }^{13}$

1) Shrinking was defined as a body mass index $<21 \mathrm{~kg} / \mathrm{m}^{2}$. Height and weight were detected by a Tanita Body Composition Analyzer BF-350 (precision level of $0.1 \mathrm{~kg}$ ) and by an anthropometer (precision level of $0.1 \mathrm{~cm}$, International Standard ISO/TR 7250-2), ${ }^{39}$ respectively. 2) Weakness was evaluated by handgrip strength. Handgrip strength was measured using a Smedley hand dynamometer (baseline 12-0286). Three attempts of maximal isometric strength were executed, with alternating limbs, and the average value of the three measurements was computed using the best mean value between right and left limb for the analysis. The same cutoff scores of the Cardiovascular Health Study were applied in this research. ${ }^{13}$ A previous study demonstrated a good level of test-retest reliability of the Smedley hand dynamometer. ${ }^{40}$ 3) Poor endurance and energy was assessed by two items from the Center of Epidemiologic Studies Depression scale (CES-D): a) "I felt that everything I did was an effort", b) "I could not get going". The statement referred to the past week. As proposed by Fried et al, ${ }^{13}$ those who answered "a moderate amount of the time (3-4 days)" or "most of the time" to at least one of the questions were positive for endurance and energy component. 4) Slowness was evaluated by the Timed Up and Go (TUG) test, ${ }^{41}$ using the reference values of Bohannon to classify subjects as frail for slowness. ${ }^{42}$ The TUG test consisted in rising from a chair, walking $3 \mathrm{~m}$, turning around a cone, walking back, and sitting down. The test was executed once, in addition to an untimed trial. 5) Low physical activity was established in the subjects who were not engaged in leisure activities, such as hiking, chores (moderately vigorous), gardening, dancing, and cycling, at least once a week. ${ }^{3}$ Subjects with three or more criteria were classified as frail, those with one or two as prefrail, and those meeting none as robust. ${ }^{13}$

\section{Psychosocial measures}

Depressive symptoms were determined with the 20-item CES-D. ${ }^{43}$ The CES-D investigates the common symptoms of depression, such as poor appetite, fatigue, and pessimism, which had occurred within the past week. The CES-D ranges from 0 (no depressive symptomatology) to 60 (severe depressive symptoms). It has been demonstrated to be a valid and reliable instrument to identify older people at risk of major depression. ${ }^{44,45}$ Following the example of Graham et al, ${ }^{46}$ the two items of CES-D used to define poor endurance according to Fried's criteria were removed. The total CES-D score is referred to 18 items, which exhibited high internal consistency in this sample $(\alpha=0.85)$.

Social isolation was evaluated using the Friendship Scale (FS). ${ }^{47} \mathrm{FS}$ is a six-item instrument investigating social relationships. Example items include: "It has been easy to relate to others", "I felt isolated from other people", and "I had someone to share my feelings with". The score ranges between 0 and 24 . Higher scores indicate social connectedness, and 
lower scores social isolation. Analysis of psychometric properties has suggested that FS is a reliable and valid instrument to be used with older adults. ${ }^{47}$ Cronbach's $\alpha$ in our sample was 0.70 .

Feeling lonely was investigated with the short version of the UCLA Loneliness scale (ULS), ${ }^{48}$ composed of eight items. This short form was derived from the Revised ULS version. ${ }^{49}$ Sample items include: "I lack companionship" and "I feel isolated from others". The total score ranged from 8 to 32 . Higher scores correspond to greater loneliness feeling. ULS is a reliable and valid instrument, commonly used with people from adolescents to older adults. ${ }^{50}$ In this study, the ULS reliability was $\alpha=0.89$.

\section{Individual characteristics}

Age, sex, living conditions, level of education, and past job were self-reported information. Questions about the condition of health were the following: 1) "Do you usually use some drugs? Yes/No" (vitamins and supplements were not considered. Only medicines consumed on a regular basis were taken into account.) 2) "Do you experience poor vision? Yes/No". 3) "Do you experience difficulties in hearing? Yes/No".

\section{Outcome measure}

The Groningen Activity Restriction Scale (GARS) is a non-disease-specific questionnaire to measure the level of autonomy in the basic and instrumental ADLs. ${ }^{51,52}$ It comprises 18 items with four categories of response. Its score ranges from 18 (absence of disability) to 72 (severe disability). The GARS is widely used with older adults. ${ }^{53,54}$ A study of Suurmeijer et al reported satisfactory results in terms of validity and reliability of the scale. ${ }^{52}$ Cronbach's $\alpha$ of 0.95 was obtained in the present study.

\section{Statistical analysis}

We presented descriptive statistics for all the variables. We examined the internal consistency of the scales with Cronbach's $\alpha$. Values of $\alpha \geq 0.70$ were considered acceptable. ${ }^{55}$ We carried out $t$-test for unpaired samples and $\chi^{2}$ test for identifying any differences between participants' subset of this study and the whole sample of the Act on Ageing project.

First, to determine differences in psychosocial adjustment (depression symptoms, social isolation, and loneliness feeling) among robust, prefrail, and frail individuals, we carried out one-way analysis of covariance (ANCOVA) using participant's age and sex as covariates and the Sidak post hoc test. Second, to individuate groups of subjects with similar psychosocial profiles (CES-D, FS, ULS), we used cluster analysis. We carried out the hierarchical cluster procedure with Ward's method, applying squared Euclidian distance followed by $k$-means clustering. Significant differences across the variables' means of the clusters were provided with one-way analysis of variance (ANOVA). Finally, to evaluate whether the physical frailty status (robust, prefrail, and frail) and the empirically identified clusters of psychosocial factors (good, moderate, and low) interact and to analyze their impact on disability, we used the two-way ANCOVA with age and sex as covariates. For each statistical significant effect, we executed the Sidak post hoc test.

For all tests, we set the level of significance at 0.05 . We conducted the statistical analysis with the Statistical Package for Social Sciences (SPSS), Version 20.0 (IBM Corporation, Armonk, NY, USA).

\section{Results}

\section{Baseline participant characteristics}

Of the 210 participants, 139 (66\%) were women. The mean age was 73.4 years (standard deviation $=5.9$, range: $65-89$ ). All the subjects lived autonomously and were retired. Most of them $(52 \%)$ were married. Forty-one percent had a level of attainment corresponding to primary school, and $62 \%$ performed manual work (eg, housewife, seamstress, worker, farmer, mason). A large number of participants $(63 \%)$ referred to having limitations in vision or hearing, or both, and $82 \%$ used at least one drug. The mean score of MMSE of 28.3 (standard deviation $=2.3$ ) confirmed the high level of cognitive functioning of the participants. According to Fried's criteria, 31\% $(n=65)$ of participants were categorized as robust, $55 \%(n=116)$ as prefrail, and $14 \%(n=29)$ as frail. The baseline characteristics of the sample are summarized in Table 1.

\section{Differences in psychosocial adjustment according to frailty status}

The one-way ANCOVA, controlling for age and sex, reported significant differences among robust, prefrail, and frail individuals for all the psychosocial variables - depression, social isolation, and feelings of loneliness. The worsening of frailty status corresponded to a significantly greater severity of each of the psychosocial variables. In respect to depression symptoms, post hoc tests revealed differences among all the three levels of frailty (robust vs prefrail, $P=0.001$; robust vs frail, $P<0.001$; prefrail vs frail, $P<0.001)$. For the social isolation, post hoc tests showed that robust individuals had higher social connectedness compared to the frail ones 
Table I Baseline characteristics of participants $(n=2 \mid 0)$

\begin{tabular}{|c|c|}
\hline Variable & Value \\
\hline Age, years, mean $\pm S D$ & $73.4 \pm 5.9$ \\
\hline \multicolumn{2}{|l|}{ Sex, n (\%) } \\
\hline Female & $139(66)$ \\
\hline Male & $71(34)$ \\
\hline \multicolumn{2}{|l|}{ Marital status, n (\%) } \\
\hline Never married & $10(5)$ \\
\hline Married & $110(52)$ \\
\hline Widow & $78(37)$ \\
\hline Divorced & $12(6)$ \\
\hline \multicolumn{2}{|l|}{ Level of education, n (\%) } \\
\hline Primary school & $87(4 I)$ \\
\hline Secondary school & $69(33)$ \\
\hline High school diploma & $43(2 I)$ \\
\hline Master's degree & $11(5)$ \\
\hline \multicolumn{2}{|l|}{ Past job, n (\%) } \\
\hline Housewife & $31(15)$ \\
\hline Manual & $98(47)$ \\
\hline Nonmanual & $81(38)$ \\
\hline \multicolumn{2}{|l|}{ Vision and hearing problems, $\mathrm{n}(\%)^{\mathrm{a}}$} \\
\hline No limitations & $77(37)$ \\
\hline Poor vision or hearing & $110(52)$ \\
\hline Both of them & $23(\mathrm{II})$ \\
\hline Pharmacotherapy, ${ }^{\mathrm{a}} \mathrm{n}(\%)$ of yes & $172(82)$ \\
\hline MMSE, mean \pm SD & $28.3 \pm 2.3$ \\
\hline $\mathrm{BMI}$, mean $\pm \mathrm{SD}$ & $28.7 \pm 4.1$ \\
\hline Handgrip strength, mean \pm SD & $25.2 \pm 8.9$ \\
\hline TUG, mean $\pm S D$ & $9.0 \pm 2.2$ \\
\hline \multicolumn{2}{|l|}{ Frailty status, $\mathrm{n}(\%)^{\mathrm{b}}$} \\
\hline Robust & $65(31)$ \\
\hline Prefrail & $116(55)$ \\
\hline Frail & $29(14)$ \\
\hline Shrinking, n (\%) of yes & $8(4)$ \\
\hline Weakness, $n(\%)$ of yes & $60(29)$ \\
\hline Poor endurance and energy, $n(\%)$ of yes & $75(36)$ \\
\hline Slowness, $n(\%)$ of yes & $40(19)$ \\
\hline Low physical activity level, $n(\%)$ of yes & $71(34)$ \\
\hline CES-D, mean $\pm S^{c}$ & $15.5 \pm 8.9$ \\
\hline $\mathrm{FS}$, mean $\pm \mathrm{SD}$ & $18.5 \pm 4.6$ \\
\hline ULS, mean \pm SD & $13.1 \pm 6.9$ \\
\hline GARS, mean \pm SD & $21.7 \pm 4.6$ \\
\hline
\end{tabular}

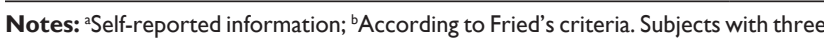
or more criteria were classified as frail, those with one or two criteria as prefrail, and those without criteria as robust; 'Excluding the two items used to investigate physical tiredness: I) "I felt that everything I did was an effort" and 2) "I could not get going". A higher score of MMSE corresponded to a better cognitive status; BMI is computed as weight divided by squared height $\left(\mathrm{kg} / \mathrm{m}^{2}\right)$; a higher score of CES-D indicated worst depressive symptomatology; a higher score of FS corresponded to stronger social connectedness; a higher score of ULS corresponded to stronger loneliness feeling; a higher score of GARS indicated severe disability.

Abbreviations: SD, standard deviation; MMSE, Mini-Mental State Examination; BMI, body mass index; TUG, Timed Up and Go test; CES-D, Center for Epidemiologic Studies Depression Scale; FS, Friendship Scale; ULS, UCLA Loneliness Scale; GARS, Groningen Activity Restriction Scale.

$(P=0.011)$. No differences in terms of social isolation were found between frail and prefrail, as well as between prefrail and robust groups. With respect to feelings of loneliness, post hoc tests revealed that robust individuals suffered less from loneliness than prefrail $(P=0.036)$ and frail individuals
$(P=0.004)$. No differences were found between prefrail and frail groups $(P>0.05)$ for feeling lonely (Table 2$)$.

\section{Effect of physical frailty and psychosocial adjustment on ADLs}

To identify groups of individuals with a similar level of psychosocial adjustment, a cluster analysis was run on the total number of participants based on their score in the CES-D, FS, and ULS scales. Hierarchical cluster analysis using Ward's method emphasized three clusters. All the cluster centers differed from each other significantly $(P<0.001)$. The first cluster included 73 subjects (35\%), and was characterized by low depressive symptoms associated with a high score of social connectedness and low loneliness feelings. The second cluster had the highest sample size $(n=100,47 \%)$. Individuals included in this cluster showed medium scores for psychosocial variables compared to the other two clusters. The third cluster was composed of 37 individuals (18\%), affected by depressive symptomatology, poor friendship network, and a high level of loneliness. The three clusters obtained were identified as "good", "moderate", and "low" level psychosocial adjustment. The descriptions of the clusters are reported in Table 3.

A two-way ANCOVA, controlling for age and sex, was conducted to determine whether the physical frailty status (robust, prefrail, and frail) and the clusters of psychosocial factors (good, moderate, and low) interact and whether they have an impact on ADLs. A major effect of physical frailty, $F(2,199)=5.15, P=0.007$, on ADLs was found. Post hoc tests showed that ADLs in frail older adults were lower compared to prefrail $(P=0.009)$ and robust individuals $(P=0.002)$. No differences in ADL were found between prefrail and robust groups $(P>0.05)$. Similarly, psychosocial factors had a main effect on ADLs, $F(2,199)=3.29, P=0.039$. Post hoc tests revealed that ADL was higher in older people having a moderate $(P=0.020)$ and good $(P=0.021)$ level of psychosocial adjustment compared to those with low psychosocial level. There were no statistical differences between individuals with moderate and good levels of psychosocial factors $(P>0.05)$ in terms of ADL. Furthermore, results showed a significant interaction of physical frailty and psychosocial clusters on ADL $, F(4,199)=3.53, P=0.008$. Specifically, a simple main effects analysis demonstrated that frail older adults with a low level of psychosocial adjustment were different in terms of ADL from frail individuals with moderate $(P<0.001)$ and good $(P=0.008)$ psychosocial scores. No differences were found for psychosocial adjustment in prefrail $(P>0.05)$ and robust subjects $(P>0.05)$. Furthermore, frail subjects with a 
Table 2 Differences between psychosocial variables for frailty status

\begin{tabular}{|c|c|c|c|c|c|c|c|c|c|}
\hline \multirow[t]{2}{*}{ Frailty } & \multicolumn{3}{|l|}{ CES-D } & \multicolumn{3}{|l|}{ FS } & \multicolumn{3}{|l|}{ ULS } \\
\hline & Mean \pm SD & $F(2,205)$ & $P$-value & Mean \pm SD & $F(2,205)$ & $P$-value & Mean \pm SD & $F(2,205)$ & $P$-value \\
\hline \multicolumn{10}{|c|}{ Frailty status } \\
\hline Frail & $23.15 \pm 9.00$ & 18.48 & $<0.001$ & $16.45 \pm 4.50$ & 4.59 & 0.011 & $16.48 \pm 6.86$ & 5.87 & 0.003 \\
\hline Prefrail & $16.20 \pm 8.37 *$ & & & $18.25 \pm 4.55$ & & & $13.68 \pm 6.75$ & & \\
\hline Robust & $10.74 \pm 6.75^{* * * *}$ & & & $\mid 9.82 \pm 4.21 *$ & & & $|0.62 \pm 6.2|^{* * * *}$ & & \\
\hline
\end{tabular}

Notes: Age and sex are used as covariates. The values of multiple comparisons were based on Sidak post hoc test: $* P<0.05$ versus frail; $* * P<0.05$ versus prefrail. For $C E S-D$ mean value, the two items used to investigate physical tiredness: I) "I felt that everything I did was an effort" and 2) "I could not get going", were excluded. A higher score of CES-D indicated worst depressive symptomatology; a higher score of FS corresponded to stronger social connectedness; a higher score of ULS corresponded to stronger loneliness feeling.

Abbreviations: CES-D, Center for Epidemiologic Studies Depression Scale; FS, Friendship Scale; ULS, UCLA Loneliness Scale; SD, standard deviation.

low level of psychosocial adjustment had lower ADL compared to the prefrail $(P<0.001)$ and robust $(P=0.002)$ within the same psychosocial group. No differences were detected for good $(P>0.05)$ and moderate $(P>0.05)$ psychosocial adjustment among frailty status (Table 4 ).

\section{Discussion}

This cross-sectional study aimed to explore the role of psychosocial factors, in association with physical frailty, in the explanation of ADL in a sample of community-dwelling older adults in Italy. First, we investigated psychosocial adjustment among people with different frailty status. Second, we tested whether there was an interactive effect of psychosocial factors and physical frailty on the ADL of older adults. In respect of frailty prevalence, our data on frail and prefrail individuals was higher than those obtained in other studies that used Fried's criteria. ${ }^{56-58}$ Closer to our findings were those from the Survey of Health, Aging and Retirement in Europe $^{59}$ and from the San Antonio Longitudinal Study of Aging. ${ }^{60}$ The slightly higher prevalence rate for the frail and prefrail obtained in our study is probably due to the typology of older adults involved in the project. In fact, one of the inclusion criteria was a sedentary lifestyle in the previous 5 years. It is possible that the absence of a regular moderate

Table 3 Description of three clusters based on scores of psychosocial variables

\begin{tabular}{lllll}
\hline $\begin{array}{llll}\text { Psychosocial } \\
\text { variables }\end{array}$ & Clusters & \multicolumn{3}{c}{ P-value* } \\
\cline { 2 - 4 } & I-good & $\mathbf{2}$ - moderate & $\mathbf{3}$ - low \\
\hline CES-D & 6.55 & 17.37 & 27.95 & $<0.001$ \\
FS & 21.66 & 18.00 & 13.52 & $<0.001$ \\
ULS & 7.64 & 13.73 & 22.27 & $<0.001$ \\
Number of cases & 73 & 100 & 37 & - \\
\hline
\end{tabular}

Notes: *Values based on one-way ANOVA. A higher score of CES-D indicated worst depressive symptomatology; a higher score of FS corresponded to stronger social connectedness; a higher score of ULS corresponded to stronger loneliness feeling.

Abbreviations: CES-D, Center for Epidemiologic Studies Depression Scale; FS, Friendship Scale; ULS, UCLA Loneliness Scale; ANOVA, analysis of variance. or vigorous physical activity is a risk factor for several components of frailty. ${ }^{61,62}$ Our findings demonstrated that physical frailty is closely tied to a significant worsening of psychosocial factors. Specifically, we found that depressive symptoms, social isolation, and feelings of loneliness are progressively higher in robust, prefrail, and frail groups. Our results are consistent with those obtained by Langlois et al, ${ }^{63}$ who showed reduced cognitive and psychological measures in frail subjects compared to robust one; of Collard et al, ${ }^{64}$ who reported an association between physical frailty and more severe depressive symptomatology in adults older than 60; and of Strawbridge et al, ${ }^{65}$ who found that robust older adults were more likely to go out for entertainment and visit with family or friends than frail subjects.

We also showed a significant interaction effect of psychosocial adjustment levels and frailty status on ADL, demonstrating that the performance of ADL differs depending on the combination of both frailty and psychosocial factors. Frail subjects with low psychosocial adjustment showed a lower level of ADL compared to frail individuals with higher psychosocial level. Similar results were found by Dent and Hoogendijk, who found interaction effects of frailty with psychosocial factors on different outcomes in a sample of hospitalized older adults. ${ }^{32}$

Our findings suggest that considering psychological and social factors - not only physical factors - may improve the explanatory contribution of "frailty" when it comes to the prediction of ADL of older adults. This may have two important implications: first, when it comes to the definition of frailty, our results suggest that a multidimensional definition that also includes psychological and social factors may be more informative and accurate in the identification of older adults at risk of negative events than a definition limited to physical factors. Second, when it comes to prevention, a multidimensional definition would allow the implementation of more focused and person-centered interventions for the prevention of frailty. Special attention should be paid to older adults who simultaneously present physical frailty and 
Table 4 Autonomy in daily activities divided by frailty status and psychosocial levels

\begin{tabular}{|c|c|c|c|c|c|c|c|c|c|}
\hline Frailty status & Robust & & & Prefrail & & & Frail & & \\
\hline $\begin{array}{l}\text { Psychosocial } \\
\text { level }\end{array}$ & $\begin{array}{l}\text { Good } \\
(n=38)\end{array}$ & $\begin{array}{l}\text { Moderate } \\
(n=24)\end{array}$ & $\begin{array}{l}\text { Low } \\
(n=3)\end{array}$ & $\begin{array}{l}\text { Good } \\
(n=32)\end{array}$ & $\begin{array}{l}\text { Moderate } \\
(n=62)\end{array}$ & $\begin{array}{l}\text { Low } \\
(n=22)\end{array}$ & $\begin{array}{l}\text { Good } \\
(n=3)\end{array}$ & $\begin{array}{l}\text { Moderate } \\
(n=\mid 4)\end{array}$ & $\begin{array}{l}\text { Low } \\
(n=12)\end{array}$ \\
\hline GARS & $20.05 \pm 3.02$ & $20.33 \pm 4.16$ & $21.33 \pm 5.77 * *$ & $21.28 \pm 3.69$ & $21.53 \pm 4.37$ & $22.14 \pm 3.52 * *$ & $21.33 \pm 3.06 *$ & $22.79 \pm 5.55 *$ & $29.67 \pm 6.20$ \\
\hline
\end{tabular}

Notes: Age and sex are used as covariates. Data are the mean $\pm S D ; * P<0.05$ versus low psychosocial level within the same physically frail group; $* * P<0.05$ versus physically frail individuals within the same psychosocial group. A higher score of GARS indicated severe disability.

Abbreviations: GARS, Groningen Activity Restriction Scale; SD, standard deviation.

a low level of psychosocial adjustment, because they are at higher risk of loss of ADL. For these individuals, intervention strategies that simultaneously act on multiple factors may be more effective than those based on a single domain. ${ }^{66}$

There are several noteworthy limitations in this study. First, research participants were representative of a small area of Italy and were included according to rigorous criteria, making it impossible to generalize the results to the entire Italian aged population. Second, the sample size was not very large, with some subgroups (eg, frail subjects) composed of a very limited number of participants. Despite the small sample size, the statistical power $(1-\beta$ err prob $=0.95)$ was reached. The high number of missing values was also a limitation of the study. Furthermore, the cross-sectional design of the research did not allow the trends of frailty and psychosocial variables to be studied longitudinally, and deepen the causal relationship between physical frailty, psychosocial factors, and clinically relevant geriatric outcomes. A further limitation concerns the absence of a wider set of geriatric clinical outcomes (eg, hospitalization, institutionalization, falls, use of health services), which did not allow the evaluation of the impact of psychosocial factors and physical frailty in a more exhaustive and complete way. Finally, the application of an adapted version of the frailty phenotype makes the comparison with results from other studies difficult, as argued by Theou et al. ${ }^{67}$

\section{Conclusion}

In conclusion, this study confirms the close relationship between physical frailty and psychosocial factors, demonstrating that the increase in physical frailty status is associated with a poor psychosocial adjustment in older adults. Moreover, it also suggests taking simultaneously into account physical and psychosocial aspects of frailty in order to better explain the adverse events of aging and to better identify older adults at risk of negative geriatric outcomes such as the loss of ADL.

\section{Acknowledgments}

For the publication of this article, a funding has been received from the project "Sistema di allerta integrato delle fragilità emergenti" within the Regional call "Bando Regionale a sostegno di progetti di ricerca industriale e/o sviluppo sperimentale di applicazioni integrate e innovative in ambito Internet of Data" funded by Regione Piemonte and the "Fondo Europeo di Sviluppo Regionale (POR-FESR)". The funding bodies were not involved in the study design, data collection, and analysis or in writing the report. Anna Mulasso and Mattia Roppolo received a research fellowship from the Department of Psychology, University of Torino (reference number 17/2015, protocol no 320), funded by "Regione Piemonte" and the "Fondo Europeo di Sviluppo Regionale (POR-FESR)" for the project "Sistema di allerta integrato delle fragilità emergenti".

\section{Disclosure}

The authors declare no potential conflicts of interest with respect to the research, authorship, and/or publication of this article.

\section{References}

1. Eurostat, editor. Population projections 2010-2060. EU27 population is expected to peak by around 2040. One person in eight aged 80 or more in 2060. Vol 80/2011. Brussels: Eurostat; 2011.

2. European Commission. EU Employment and Social Situation, Quarterly Review, Special Supplement on Demographic Trends. Brussels: European Commission; 2013.

3. Avila-Funes JA, Amieva H, Barberger-Gateau P, et al. Cognitive impairment improves the predictive validity of the phenotype of frailty for adverse health outcomes: the three-city study. J Am Geriatr Soc. 2009; 57(3):453-461.

4. van Kan GA, Rolland Y, Bergman H, Morley JE, Kritchevsky SB, Vellas B. The I.A.N.A Task Force on frailty assessment of older people in clinical practice. J Nutr Health Aging. 2008;12(1):29-37.

5. Bergman H, Ferrucci L, Guralnik J, et al. Frailty: an emerging research and clinical paradigm - issues and controversies. J Gerontol A Biol Sci Med Sci. 2007;62(7):731-737.

6. Gobbens RJ, van Assen MA, Luijkx KG, Wijnen-Sponselee MT, Schols JM. Determinants of frailty. J Am Med Dir Assoc. 2010;11(5): 356-364.

7. Heppenstall CP, Wilkinson TJ, Hanger HC, Keeling S. Frailty: dominos or deliberation? N Z Med J. 2009;122(1299):42-53.

8. Lin CC, Li CI, Meng NH, et al. Frailty and its associated factors in an elderly taiwanese metropolitan population. J Am Geriatr Soc. 2013 61(2):292-294.

9. Vermeulen J, Neyens JC, van Rossum E, Spreeuwenberg MD, de Witte LP. Predicting ADL disability in community-dwelling elderly people using physical frailty indicators: a systematic review. BMC Geriatr. 2011;11:33 
10. Walston J. Frailty - the search for underlying causes. Sci Aging Knowledge Environ. 2004;2004(4):e4.

11. Collard RM, Boter H, Schoevers RA, Oude Voshaar RC. Prevalence of frailty in community-dwelling older persons: a systematic review. J Am Geriatr Soc. 2012;60(8):1487-1492.

12. Carriere I, Colvez A, Favier F, Jeandel C, Blain H. Hierarchical components of physical frailty predicted incidence of dependency in a cohort of elderly women. J Clin Epidemiol. 2005;58(11):1180-1187.

13. Fried LP, Tangen CM, Walston J, et al; Cardiovascular Health Study Collaborative Research Group. Frailty in older adults: evidence for a phenotype. J Gerontol A Biol Sci Med Sci. 2001;56(3): M146-M156.

14. Gloth FM 3rd, Walston J, Meyer J, Pearson J. Reliability and validity of the Frail Elderly Functional Assessment questionnaire. Am J Phys Med Rehabil. 1995;74(1):45-53.

15. Bilotta C, Bowling A, Casè A, et al. Dimensions and correlates of quality of life according to frailty status: a cross-sectional study on community-dwelling older adults referred to an outpatient geriatric service in Italy. Health Qual Life Outcomes. 2010;8:56.

16. Drubbel I, de Wit NJ, Bleijenberg N, Eijkemans RJ, Schuurmans MJ, Numans ME. Prediction of adverse health outcomes in older people using a frailty index based on routine primary care data. $J$ Gerontol $A$ Biol Sci Med Sci. 2013;68(3):301-308.

17. Hubbard RE, Andrew MK, Fallah N, Rockwood K. Comparison of the prognostic importance of diagnosed diabetes, co-morbidity and frailty in older people. Diabet Med. 2010;27(5):603-606.

18. Rothman MD, Leo-Summers L, Gill TM. Prognostic significance of potential frailty criteria. $J$ Am Geriatr Soc. 2008;56(12):2116-2211.

19. Stuck AE, Walthert JM, Nikolaus T, Bula CJ, Hohmann C, Beck JC. Risk factors for functional status decline in community-living elderly people: a systematic literature review. Soc Sci Med. 1999;48(4):445-469.

20. Beekman AT, Deeg DJ, Van Limbeek J, Braam AW, De Vries MZ, Van Tilburg W. Criterion validity of the Center for Epidemiologic Studies Depression scale (CES-D): results from a community-based sample of older subjects in the Netherlands. Psychol Med. 1997;27(1): 231-235.

21. de Beurs E, Beekman AT, van Balkom AJ, Deeg DJ, van Dyck R, van Tilburg W. Consequences of anxiety in older persons: its effect on disability, well-being and use of health services. Psychol Med. 1999; 29(3):583-593.

22. Berkman LF. The role of social relations in health promotion. Psychosom Med. 1995;57(3):245-254.

23. House JS, Landis KR, Umberson D. Social relationships and health. Science. 1988;241(4865):540-545.

24. Tomaka J, Thompson S, Palacios R. The relation of social isolation, loneliness, and social support to disease outcomes among the elderly. J Aging Health. 2006;18(3):359-384.

25. Gobbens RJ, Luijkx KG, Wijnen-Sponselee MT, Schols JM. In search of an integral conceptual definition of frailty: opinions of experts. $J \mathrm{Am}$ Med Dir Assoc. 2010;11(5):338-343.

26. Markle-Reid M, Browne G. Conceptualizations of frailty in relation to older adults. $J$ Adv Nurs. 2003;44(1):58-68

27. Walston J, Hadley EC, Ferrucci L, et al. Research agenda for frailty in older adults: toward a better understanding of physiology and etiology: summary from the American Geriatrics Society/National Institute on Aging Research Conference on Frailty in Older Adults. $J$ Am Geriatr Soc. 2006;54(6):991-1001.

28. Engel GL. The need for a new medical model: a challenge for biomedicine. Science. 1977;196(4286):129-136.

29. Borrell-Carrio F, Suchman AL, Epstein RM. The biopsychosocial model 25 years later: principles, practice, and scientific inquiry. Ann Fam Med. 2004;2(6):576-582.

30. Fulop T, Larbi A, Witkowski JM, et al. Aging, frailty and age-related diseases. Biogerontology. 2010;11(5):547-563.

31. Gobbens RJ, Luijkx KG, Wijnen-Sponselee MT, Schols JM. Towards an integral conceptual model of frailty. J Nutr Health Aging. 2010; 14(3):175-181.
32. Dent E, Hoogendijk EO. Psychosocial factors modify the association of frailty with adverse outcomes: a prospective study of hospitalised older people. BMC Geriatr. 2014;14:108.

33. Hoogendijk EO, van Hout HP, van der Horst HE, et al. Do psychosocial resources modify the effects of frailty on functional decline and mortality? J Psychosom Res. 2014;77(6):547-551.

34. Gobbens RJ, van Assen MA, Luijkx KG, Schols JM. The predictive validity of the Tilburg Frailty Indicator: disability, health care utilization, and quality of life in a population at risk. Gerontologist. 2012;52(5):619-631.

35. Gobbens RJ, Luijkx KG, van Assen MA. Explaining quality of life of older people in the Netherlands using a multidimensional assessment of frailty. Qual Life Res. 2012;22(8):2051-2061.

36. Ament BH, de Vugt ME, Verhey FR, Kempen GI. Are physically frail older persons more at risk of adverse outcomes if they also suffer from cognitive, social, and psychological frailty? Eur J Ageing. 2014;11(3):213-219.

37. Folstein MF, Folstein SE, McHugh PR. "Mini-mental state". A practical method for grading the cognitive state of patients for the clinician. J Psychiatr Res. 1975;12(3):189-198.

38. Ethical principles of psychologists and code of conduct. Am Psychol. 2002;57(12):1060-1073.

39. International Standard ISO/TR 7250-2. Basic human body measurements for technological design. Part 2: statistical summaries of body measurements from individual ISO populations; 2010, Geneva, Switzerland.

40. Metter EJ, Talbot LA, Schrager M, Conwit R. Skeletal muscle strength as a predictor of all-cause mortality in healthy men. $J$ Gerontol A Biol Sci Med Sci. 2002;57(10):B359-B365.

41. Podsiadlo D, Richardson S. The timed "Up \& Go": a test of basic functional mobility for frail elderly persons. J Am Geriatr Soc. 1991;39(2): 142-148.

42. Bohannon RW. Reference values for the timed up and go test: a descriptive meta-analysis. J Geriatr Phys Ther. 2006;29(2):64-68.

43. Radloff LS. The CES-D Scale: a self-report depression scale forresearch in the general population. Appl Psych Meas. 1977;1(3):385-401.

44. Davidson H, Feldman PH, Crawford S. Measuring depressive symptoms in the frail elderly. J Gerontol. 1994;49(4):159-164.

45. Dufouil C, Fuhrer R, Dartigues JF, Alperovitch A. Longitudinal analysis of the association between depressive symptomatology and cognitive deterioration. Am J Epidemiol. 1996;144(7):634-641.

46. Graham JE, Snih SA, Berges IM, Ray LA, Markides KS, Ottenbacher KJ. Frailty and 10-year mortality in community-living Mexican American older adults. Gerontology. 2009;55(6):644-651.

47. Hawthorne G. Measuring social isolation in older adults: development and initial validation of the Friendship Scale. Soc Indic Res. 2006;77:521-548.

48. Hays RD, DiMatteo MR. A short-form measure of loneliness. $J$ Pers Assess. 1987;51(1):69-81.

49. Russell D, Peplau LA, Cutrona CE. The revised UCLA Loneliness Scale: concurrent and discriminant validity evidence. J Pers Soc Psychol. 1980;39(3):472-480.

50. Russell DW. UCLA Loneliness Scale (Version 3): reliability, validity, and factor structure. J Pers Assess. 1996;66(1):20-40.

51. Kempen GI, Suurmeijer TP. The development of a hierarchical polychotomous ADL-IADL scale for noninstitutionalized elders. Gerontologist. 1990;30(4):497-502.

52. Suurmeijer TP, Doeglas DM, Moum T, et al. The Groningen Activity Restriction Scale for measuring disability: its utility in international comparisons. Am J Public Health. 1994;84(8):1270-1273.

53. Faber MJ, Bosscher RJ, Chin APMJ, van Wieringen PC. Effects of exercise programs on falls and mobility in frail and pre-frail older adults: a multicenter randomized controlled trial. Arch Phys Med Rehabil. 2006;87(7):885-896.

54. Tak E, Staats P, Van Hespen A, Hopman-Rock M. The effects of an exercise program for older adults with osteoarthritis of the hip. J Rheumatol. 2005;32(6):1106-1113. 
55. Nunnally JC, Bernstein IH. Psychometric Theory. 3rd ed. New York City, NY: McGraw-Hill; 1994.

56. Avila-Funes JA, Aguilar-Navarro S, Melano-Carranza E. La fragilidad, concepto enigmático y controvertido de la geriatría. La visión biológica [Frailty, an enigmatic and controversial concept in geriatrics. The biological perspective]. Gac Med Mex. 2008;144(3):255-262.

57. Blyth FM, Rochat S, Cumming RG, et al. Pain, frailty and comorbidity on older men: the CHAMP study. Pain. 2008;140(1):224-230.

58. Chen CY, Wu SC, Chen LJ, Lue BH. The prevalence of subjective frailty and factors associated with frailty in Taiwan. Arch Gerontol Geriatr. 2010;50(suppl 1):S43-S47.

59. Santos-Eggimann B, Cuenoud P, Spagnoli J, Junod J. Prevalence of frailty in middle-aged and older community-dwelling Europeans living in 10 countries. J Gerontol A Biol Sci Med Sci. 2009;64(6):675-681.

60. Espinoza SE, Jung I, Hazuda H. Lower frailty incidence in older Mexican Americans than in older European Americans: the San Antonio Longitudinal Study of Aging. J Am Geriatr Soc. 2010;58(11):2142-2148.

61. Landi F, Abbatecola AM, Provinciali M, et al. Moving against frailty: does physical activity matter? Biogerontology. 2010;11(5):537-545.

62. Peterson MJ, Giuliani C, Morey MC, et al; Health, Aging and Body Composition Study Research Group. Physical activity as a preventative factor for frailty: the health, aging, and body composition study. J Gerontol A Biol Sci Med Sci. 2009;64(1):61-68.
63. Langlois F, Vu TT, Kergoat MJ, Chasse K, Dupuis G, Bherer L. The multiple dimensions of frailty: physical capacity, cognition, and quality of life. Int Psychogeriatr. 2012;24(9):1429-1436.

64. Collard RM, Comijs HC, Naarding P, Oude Voshaar RC. Physical frailty: vulnerability of patients suffering from late-life depression. Aging Ment Health. 2014;18(5):570-578.

65. Strawbridge WJ, Shema SJ, Balfour JL, Higby HR, Kaplan GA. Antecedents of frailty over three decades in an older cohort. J Gerontol B Psychol Sci Soc Sci. 1998;53(1):S9-S16.

66. Schneider N, Yvon C. A review of multidomain interventions to support healthy cognitive ageing. J Nutr Health Aging. 2013;17(3):252-257.

67. Theou O, Cann L, Blodgett J, Wallace LM, Brothers TD, Rockwood K. Modifications to the frailty phenotype criteria: systematic review of the current literature and investigation of 262 frailty phenotypes in the survey of health, ageing, and retirement in Europe. Ageing Res Rev. 2015;21:78-94.
Clinical Interventions in Aging

\section{Publish your work in this journal}

Clinical Interventions in Aging is an international, peer-reviewed journal focusing on evidence-based reports on the value or lack thereof of treatments intended to prevent or delay the onset of maladaptive correlates of aging in human beings. This journal is indexed on PubMed Central, MedLine,

\section{Dovepress}

CAS, Scopus and the Elsevier Bibliographic databases. The manuscript management system is completely online and includes a very quick and fair peer-review system, which is all easy to use. Visit http://www.dovepress. com/testimonials.php to read real quotes from published authors. 